\title{
An Isovelocity Dynamometer Method to Determine Monoarticular and Biarticular Muscle Parameters
}

\author{
Filipe Conceição, ${ }^{1}$ Mark A. King,, ${ }^{2}$ Maurice R. Yeadon, ${ }^{2}$ \\ Martin G.C. Lewis, ${ }^{2}$ and Stephanie E. Forrester ${ }^{2}$ \\ 1 University of Porto; ${ }^{2}$ Loughborough University
}

\begin{abstract}
This study aimed to determine whether subject-specific individual muscle models for the ankle plantar flexors could be obtained from single joint isometric and isovelocity maximum torque measurements in combination with a model of plantar flexion. Maximum plantar flexion torque measurements were taken on one subject at six knee angles spanning full flexion to full extension. A planar three-segment (foot, shank and thigh), twomuscle (soleus and gastrocnemius) model of plantar flexion was developed. Seven parameters per muscle were determined by minimizing a weighted root mean square difference (wRMSD) between the model output and the experimental torque data. Valid individual muscle models were obtained using experimental data from only two knee angles giving a wRMSD score of $16 \mathrm{~N} \mathrm{~m}$, with values ranging from 11 to $17 \mathrm{~N} \mathrm{~m}$ for each of the six knee angles. The robustness of the methodology was confirmed through repeating the optimization with perturbed experimental torques $( \pm 20 \%)$ and segment lengths $( \pm 10 \%)$ resulting in wRMSD scores of between 13 and $20 \mathrm{~N} \mathrm{~m}$. Hence, good representations of maximum torque can be achieved from subject-specific individual muscle models determined from single joint maximum torque measurements. The proposed methodology could be applied to muscle-driven models of human movement with the potential to improve their validity.
\end{abstract}

Keywords: plantar flexion, gastrocnemius, soleus, dynamometer

Computer simulation models are widely used to study neuromuscular aspects of human movement. The models are commonly muscle-driven in which the force generating capacity of the muscle is described by a Hill-type model using muscle parameters scaled from the literature based on an individual's anthropometrics and maximum isometric torque, for example, Jacobs et al. (1996). Literature parameters typically originate from animal or human cadavers, that is, quite different populations to those of interest, and a wide range of values have been reported. Several studies have highlighted the sensitivity of muscle force prediction to the parameter values selected, for example, Scovil \& Ronsky (2006). Hence, although muscle-driven computer simulation models have strong potential for the assessment of human performance (e.g., in estimating internal forces), uncertainty in the accuracy of the individual muscle models that contribute to these simulation models can result in their poor evaluation and threaten the validity of the simulation model outputs (Yeadon \& Challis, 1994).

Filipe Conceição is with the Sports Faculty, University of Porto, Porto, Portugal. Mark A. King, Maurice R. Yeadon, and Martin G.C. Lewis are with the School of Sport, Exercise and Health Sciences, Loughborough University, Loughborough, UK. Stephanie E. Forrester (Corresponding Author) is with the Wolfson School of Mechanical and Manufacturing Engineering, Loughborough University, Loughborough, UK.
An alternative is to use torque-driven models in which all the muscles crossing a joint are lumped together to form a single torque generator, for example, King et al. (2006). The advantage is that subject-specific torque functions can readily be obtained from maximum torque measurements on an isovelocity dynamometer (Yeadon et al., 2006); the disadvantage is limitations in the type of questions that can be addressed since individual muscle contributions cannot be resolved. This study aimed to determine whether the established approach to obtain subject-specific torque profiles could be extended to provide subject-specific individual muscle models for use in muscle-driven models of human movement with the potential to improve their validity.

\section{Methods}

Individual muscle parameters for the ankle plantar flexors, (the monoarticular soleus and biarticular gastrocnemius) were obtained from maximum torque measurements at a single joint. As knee angle is varied, the ability of the gastrocnemius to generate plantar flexion torque also varies while that of the soleus remains constant. Thus, the individual muscle parameters can be resolved by measuring ankle plantar flexion strength at different knee angles and using this data in a systematic optimization approach applied to a musculoskeletal model of 
plantar flexion. The number of knee angles required to gain valid individual muscle models, and the robustness of the methodology to perturbations in the experimental dataset were investigated.

One male athletic subject (age 36 , height $1.78 \mathrm{~m}$, mass $91 \mathrm{~kg}$ ) with no history of neural or musculoskeletal injuries to the lower leg gave written informed consent as approved by Loughborough University Ethical Advisory Committee. A CON-TREX Multijoint System (CMV $\mathrm{AG}$, Switzerland) isovelocity dynamometer was used to measure plantar flexion torques for maximal isometric, eccentric and concentric contractions. The subject was positioned supine on the dynamometer with his hips and upper body strapped tightly down, the foot of his dominant leg strapped tightly to the dynamometer and his lateral malleolus aligned with the crank arm axis of rotation. A series of isometric and isovelocity ankle plantar flexion trials were collected at six knee angles $\left(168^{\circ}, 145^{\circ}, 135^{\circ}, 125^{\circ}, 110^{\circ}\right.$ and $45^{\circ}$, where $180^{\circ}$ corresponded to a straight leg). These angles did not include the very extremes in the subject's range of motion to avoid possible neural inhibition effects (Forrester \& Pain, 2010). For each knee angle, trials were performed at six isometric ankle angles covering the full range of motion and six repeated concentric-eccentric contractions at angular velocities between 50 and $300 \%$ s. The isovelocity trials involved two to five repetitions of a concentric-eccentric cycle where the initial repetition was designed to provide the preactivation necessary to ensure that the central cycles were maximal (Yeadon et al., 2006). Knee angle was measured using a mechanical goniometer and ankle angle was assumed to be the same as crank angle. The subject was given a rest interval of at least $90 \mathrm{~s}$ between trials and 5 min between knee angles and he was verbally encouraged to maximally perform plantar flexion throughout. Finally, an isometric and an isovelocity trial from the first knee angle were repeated to test for reliability and fatigue.
The dynamometer data were sampled at $512 \mathrm{~Hz}$ and low pass filtered at $8 \mathrm{~Hz}$ using a fourth-order zero-lag Butterworth filter. For each isometric trial, the maximum torque value was determined. For each isovelocity trial, the concentric contraction and eccentric contraction with highest isovelocity torques were selected and the torque-angle data fitted using quintic splines (Wood \& Jennings, 1979) to give values every $1^{\circ}$. This process resulted in a three-dimensional array of ankle plantar flexion torque-angle-angular velocity data for each of the six knee angles and provided the experimental input to the muscle parameter optimization process.

A planar three rigid segment (foot, shank, thigh; Figure 1) model of plantar flexion was developed with segment lengths obtained from anthropometric measurements. The soleus (SOL) and gastrocnemius (GAS) were assumed to provide plantar flexion torque with the gastrocnemius also crossing the knee. A Hill-type model comprising a contractile element and series elastic element described the behavior of each muscle. Maximum voluntary muscle force $(F)$ and total plantar flexion torque $\left(T_{P F}\right)$ and were calculated from

$$
\begin{gathered}
F=a c t \times F_{o} \times f_{L} \times f_{V} \\
T_{P F}=F_{G A S} \times r_{G A S}+F_{S O L} \times r_{S O L}
\end{gathered}
$$

where voluntary activation was assumed to be maximal throughout $(a c t=1), F_{o}$ was maximum isometric force, the normalized force-length function $f_{L}$ was modeled as a quadratic (Jacobs et al., 1996), and the normalized tetanic force-velocity function $f_{V}$ was described by two hyperbolae representing the concentric and eccentric phases respectively (Yeadon et al., 2006). The series elastic element was assumed to have linear stiffness over the experimental range and a stretch of $5 \%$ at maximum isometric force (Finni \& Komi, 2002). Moment arm $r$ was

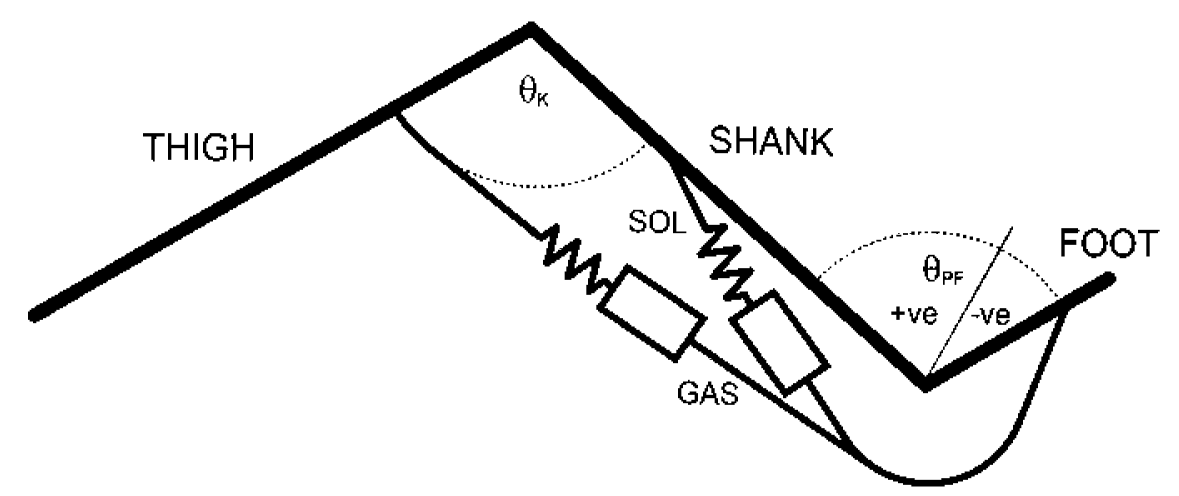

Figure 1 - Schematic of the planar three-rigid-segment (foot, shank, thigh), two-muscle (soleus and gastrocnemius) model for ankle plantar flexion. Ankle angle $\left(\theta_{P F}\right)$ is measured from the neutral position; dorsiflexion is positive and plantar flexion is negative. Knee angle $\left(\boldsymbol{\theta}_{K}\right)$ is measured as the internal angle between the shank and thigh. 
modeled as a quadratic function of joint angle (Visser et al., 1990; Rugg et al., 1990) and the total length of the muscle-tendon unit was obtained from Friederich and Brand (1990). Both moment arm and muscle-tendon unit length were scaled to the subject segment lengths.

The force production model for each muscle was described by seven parameters. The force-velocity relationship was defined by the following: maximum eccentric force, maximum isometric force, maximum shortening velocity and curvature of the concentric hyperbola (the ratio of slopes at zero angular velocity was taken to be 4.3; Huxley, 1957). The force-length relationship was defined by the width of the curve and optimal length. Behavior of the series elastic element was defined by a single parameter: slack length. These fourteen muscle parameter values were optimized to minimize the difference between experimental and model plantar flexion torques. The optimization used a genetic algorithm (Chipperfield et al., 1994), which is known as a robust means for obtaining a global optimum in multivariable problems with complex cost surfaces (Haupt $\&$ Haupt, 2004). The cost function was a weighted root mean square difference (wRMSD), which forced $90 \%$ of the experimental data to lie beneath the model strength surface. The weighting was in recognition that experimental torque can underestimate maximum torque. The genetic algorithm required an upper and lower bound for each parameter, which were selected to encompass the range of literature values (Table 1).

To investigate the validity of the resulting muscle models and the robustness of the methodology, optimizations were conducted for the following conditions: (1) using only the experimental data from a reduced number of knee angles (from all six down to only one); (2) perturbing the experimental data through changing torques by $\pm 20 \%$ and segment lengths by $\pm 10 \%$.

\section{Results}

Optimizations using the experimental torque data from between one and six knee angles gave wRMSD scores ranging from 9 to $16 \mathrm{~N} \cdot \mathrm{m}$, corresponding to $5-8 \%$ of maximum isometric torque at the most extended knee angle (Figure 2 and Table 2). Optimizations using two or more knee angles gave similar and consistent wRMSD values across all six individual knee angles regardless of whether they had been included in the optimization. However, for the single knee angle optimization, the wRMSD values were over a factor of 10 higher at knee angles distant from that used in the optimization.

Based on the above results, the optimizations for the perturbed experimental torques and segment lengths used only the data from two knee angles (most extended and most flexed). These gave wRMSD scores ranging from 13 to $20 \mathrm{~N} \cdot \mathrm{m}$, corresponding to $7-8 \%$ of maximum isometric torque at the most extended knee angle (Figure 3 and Table 3). Furthermore, the wRMSD values across all six individual knee angles were consistently in the range $8-23 \mathrm{~N} \cdot \mathrm{m}$.

The repeated trials gave peak torque measurements within $5 \%$ of the original values, confirming that fatigue effects were small.

Table 1 Upper (UB) and lower (LB) bounds used for each muscle parameter in the optimizations

\begin{tabular}{|c|c|c|c|c|c|c|}
\hline \multirow[b]{2}{*}{ Optimization } & \multirow[b]{2}{*}{ Parameter } & \multicolumn{2}{|c|}{ SOL } & \multicolumn{2}{|c|}{ GAS } & \multirow[b]{2}{*}{ Literature Source } \\
\hline & & LB & UB & LB & UB & \\
\hline \multirow{4}{*}{ Isometric } & $\mathrm{L}_{\mathrm{tsl}}(\mathrm{m})$ & 0.26 & 0.38 & 0.35 & 0.51 & Böhm et al. (2006) \\
\hline & Width $(-)$ & 0.28 & 1.12 & 0.28 & 1.12 & Winters \& Woo (1990) \\
\hline & $\mathrm{L}_{\mathrm{opt}}(\mathrm{m})$ & 0.029 & 0.077 & 0.034 & 0.090 & Böhm et al. (2006) \\
\hline & $\mathrm{F}_{\mathrm{o}}(\mathrm{N})$ & 2430 & 6470 & 840 & 2250 & Winters \& Woo (1990) \\
\hline \multirow{7}{*}{ Dynamic } & $\mathrm{L}_{\mathrm{tsl}}(\mathrm{m})$ & \multicolumn{4}{|c|}{ Isometric optimization value, $\pm 5 \%$} & - \\
\hline & Width $(-)$ & \multicolumn{4}{|c|}{ Isometric optimization value, $\pm 5 \%$} & - \\
\hline & $\mathrm{L}_{\mathrm{opt}}(\mathrm{m})$ & \multicolumn{4}{|c|}{ Isometric optimization value, $\pm 5 \%$} & - \\
\hline & $\mathrm{F}_{\mathrm{o}}(\mathrm{N})$ & \multicolumn{4}{|c|}{ Isometric optimization value, $\pm 15 \%$} & - \\
\hline & $\mathrm{V}_{\max }\left(\mathrm{L}_{\mathrm{opt}} \mathrm{s}^{-1}\right)$ & 3.0 & 12.0 & 3.0 & 12.0 & Winters \& Woo (1990) \\
\hline & $\mathrm{F}_{\mathrm{ecc}} / \mathrm{F}_{\mathrm{o}}(-)$ & 1.0 & 1.6 & 1.0 & 1.6 & Yeadon et al. (2006) \\
\hline & $\mathrm{V}_{\mathrm{c}} / \mathrm{V}_{\max }(-)$ & 0.15 & 0.50 & 0.15 & 0.50 & Yeadon et al. (2006) \\
\hline
\end{tabular}

Note. $\mathrm{L}_{\mathrm{ts} 1}=$ tendon slack length; width $=$ width of force-length curve; $\mathrm{L}_{\mathrm{opt}}=$ optimal fiber length; $\mathrm{F}_{\mathrm{o}}=$ maximum voluntary isometric force; $\mathrm{V}_{\max }$ $=$ maximum shortening velocity; $F_{\text {ecc }}=$ maximum voluntary eccentric force; $-V_{\mathfrak{c}}=$ vertical asymptote of concentric hyperbola. The optimizations were performed in a two-stage process (isometric followed by dynamic) as described in Forrester et al. (2011). 
Table 2 Soleus and gastrocnemius muscle parameters obtained from the optimizations using the experimental data from different combinations of knee angles

\begin{tabular}{|c|c|c|c|c|c|}
\hline \multirow[b]{2}{*}{ Muscle } & \multirow[b]{2}{*}{ Parameter } & \multicolumn{4}{|c|}{ Experimental } \\
\hline & & $6 \times \theta_{K}$ & $2 \mathbf{a} \times \theta_{K}$ & $2 \mathbf{b} \times \theta_{K}$ & $1 \times \theta_{K}$ \\
\hline \multirow{7}{*}{ SOL } & $\mathrm{L}_{\mathrm{tsl}}(\mathrm{m})$ & 0.276 & 0.279 & 0.286 & 0.293 \\
\hline & Width (-) & 0.936 & 0.919 & 0962 & 0.624 \\
\hline & $\mathrm{L}_{\mathrm{opt}}(\mathrm{m})$ & 0.0773 & 0.0728 & 0.0680 & 0.0485 \\
\hline & $\mathrm{F}_{\mathrm{o}}(\mathrm{N})$ & 3051 & 3502 & 3849 & 3084 \\
\hline & $V_{\max }\left(L_{o p t} s^{-1}\right)$ & 11.9 & 11.7 & 11.7 & 12.0 \\
\hline & $\mathrm{F}_{\mathrm{ecc}} / \mathrm{F}_{\mathrm{o}}(-)$ & 1.39 & 1.10 & 1.18 & 1.42 \\
\hline & $\mathrm{V}_{\mathrm{c}} / \mathrm{V}_{\max }(-)$ & 0.338 & 0.423 & 0.394 & 0.290 \\
\hline \multirow{7}{*}{ GAS } & $\mathrm{L}_{\mathrm{tsl}}(\mathrm{m})$ & 0.418 & 0.424 & 0.447 & 0.437 \\
\hline & Width (-) & 0.437 & 0.436 & 0.776 & 1.201 \\
\hline & $\mathrm{L}_{\mathrm{opt}}(\mathrm{m})$ & 0.0513 & 0.0447 & 0.0469 & 0.0699 \\
\hline & $\mathrm{F}_{\mathrm{o}}(\mathrm{N})$ & 1728 & 1686 & 2079 & 1927 \\
\hline & $\mathrm{V}_{\max }\left(\mathrm{L}_{\mathrm{opt}} \mathrm{s}^{-1}\right)$ & 10.8 & 11.9 & 11.8 & 12.0 \\
\hline & $\mathrm{F}_{\mathrm{ecc}} / \mathrm{F}_{\mathrm{o}}(-)$ & 1.13 & 1.13 & 1.13 & 1.55 \\
\hline & $\mathrm{V}_{\mathrm{c}} / \mathrm{V}_{\max }(-)$ & 0.155 & 0.254 & 0.253 & 0.415 \\
\hline \multicolumn{2}{|c|}{$\begin{array}{l}\text { wRMSD score }(\mathrm{N} \cdot \mathrm{m}) \\
\text { (i.e., included } \theta_{\mathrm{K}} \text { only) }\end{array}$} & 16 & 16 & 9 & 10 \\
\hline \multirow{6}{*}{$\begin{array}{l}\text { wRMSD }(\mathrm{N} \cdot \mathrm{m}) \\
\text { for the } \\
\text { individual } \theta_{\mathrm{K}}\end{array}$} & $168^{\circ}$ & 17 & 17 & 13 & 10 \\
\hline & $155^{\circ}$ & 12 & 11 & 8 & 31 \\
\hline & $145^{\circ}$ & 14 & 13 & 11 & 31 \\
\hline & $135^{\circ}$ & 16 & 15 & 14 & 23 \\
\hline & $110^{\circ}$ & 13 & 11 & 10 & 153 \\
\hline & $45^{\circ}$ & 23 & 16 & 15 & 389 \\
\hline \multicolumn{2}{|c|}{$\begin{array}{c}\text { Overall wRMSD }(\mathrm{N} \cdot \mathrm{m}) \\
\left.\text { (i.e., all } 6 \theta_{\mathrm{K}}\right)\end{array}$} & 16 & 14 & 12 & 50 \\
\hline
\end{tabular}

Note. (1) Experimental: $6 \times \theta_{\mathrm{K}}=168^{\circ}, 155^{\circ}, 145^{\circ}, 135^{\circ}, 110^{\circ}$ and $45^{\circ} ; 2 \mathrm{a} \times \theta_{\mathrm{K}}=168^{\circ}$ and $45^{\circ} ; 2 \mathrm{~b} \times \theta_{\mathrm{K}}=$ $155^{\circ}$ and $110^{\circ} ; 1 \times \theta_{\mathrm{K}}=168^{\circ}$. (2) In the third block of numbers, the gray boxes contain wRMSD values for knee angles that were not included in the optimization, and the white boxes contain values for knee angles that were included.

\section{Discussion}

This study aimed to determine whether subject-specific individual muscle models for the ankle plantar flexors could be obtained from single joint isometric and isovelocity maximum torque measurements in combination with a model of plantar flexion, and whether the methodology was suitable for application to muscle-driven models of human motion. It was shown that a robust set of muscle parameters could be obtained from strength measurements at only two knee angles, giving a wRMSD score of $16 \mathrm{~N} \cdot \mathrm{m}$ and values for the individual knee angles of between 11 and $17 \mathrm{~N} \cdot \mathrm{m}$. These individual knee angle scores include the two angles used in the optimization process and a further four knee angles not used in the optimization, supporting the validity of the muscle models obtained. The optimizations performed with the experimental torques and segment lengths perturbed resulted in similar wRMSD scores to the unperturbed case, of between 13 and $20 \mathrm{~N} \cdot \mathrm{m}$, supporting the robustness of the proposed methodology. The requirement for plantar flexion measurements at only two knee angles suggests that this is a realistic and robust methodology for obtaining subject-specific individual muscle models for application in muscle-driven models of human motion.

For the neutral ankle position and two most flexed knee angles $\left(110^{\circ}\right.$ and $\left.45^{\circ}\right)$, the gastrocnemius did not contribute to ankle plantar flexion as the muscle fibers were too short. Thereafter, the gastrocnemius contribution increased toward knee extension, which resulted in an approximately $65 \%$ increase in total plantar flexion torque between the most flexed and extended knee angles $\left(45^{\circ}\right.$ 
Table 3 Soleus and gastrocnemius muscle parameters obtained from the optimizations with perturbations of $\pm 20 \%$ in experimental strength and $\pm 10 \%$ in segment lengths. All optimizations are based on the experimental data from the two extreme knee angles (2a in Table 2).

\begin{tabular}{|c|c|c|c|c|c|c|}
\hline \multirow[b]{2}{*}{ Muscle } & \multirow[b]{2}{*}{ Parameter } & \multicolumn{5}{|c|}{ Experimental } \\
\hline & & $\begin{array}{l}\text { Original } \\
2 \mathrm{a} \times \theta_{\mathrm{K}}\end{array}$ & $\begin{array}{c}120 \% \\
\text { Strength }\end{array}$ & $\begin{array}{c}\mathbf{8 0} \% \\
\text { Strength }\end{array}$ & $\begin{array}{c}110 \% \\
\text { Length }\end{array}$ & $\begin{array}{c}90 \% \\
\text { Length }\end{array}$ \\
\hline \multirow{7}{*}{$\mathrm{SOL}$} & $\mathrm{L}_{\mathrm{tsl}}(\mathrm{m})$ & 0.279 & 0.279 & 0.277 & 0.327 & 0.236 \\
\hline & Width (-) & 0.919 & 0.920 & 0.881 & 1.052 & 0.799 \\
\hline & $\mathrm{L}_{\mathrm{opt}}(\mathrm{m})$ & 0.0728 & 0.0687 & 0.0797 & 0.0767 & 0.0694 \\
\hline & $\mathrm{F}_{\mathrm{o}}(\mathrm{N})$ & 3502 & 3891 & 2989 & 3526 & 3601 \\
\hline & $\mathrm{V}_{\max }\left(\mathrm{L}_{\mathrm{opt}} \mathrm{s}^{-1}\right)$ & 11.7 & 12.0 & 11.7 & 11.9 & 12.0 \\
\hline & $\mathrm{F}_{\mathrm{ecc}} / \mathrm{F}_{\mathrm{o}}(-)$ & 1.10 & 1.13 & 1.10 & 1.10 & 1.21 \\
\hline & $\mathrm{V}_{\mathrm{c}} / \mathrm{V}_{\max }(-)$ & 0.423 & 0.409 & 0.344 & 0.397 & 0.414 \\
\hline \multirow{7}{*}{ GAS } & $\mathrm{L}_{\mathrm{ts} 1}(\mathrm{~m})$ & 0.424 & 0.425 & 0.425 & 0.481 & 0.373 \\
\hline & Width (-) & 0.436 & 0.439 & 0.436 & 0.543 & 0.437 \\
\hline & $\mathrm{L}_{\mathrm{opt}}(\mathrm{m})$ & 0.0447 & 0.0461 & 0.0443 & 0.0495 & 0.0389 \\
\hline & $\mathrm{F}_{\mathrm{o}}(\mathrm{N})$ & 1686 & 2179 & 1417 & 1604 & 2144 \\
\hline & $V_{\max }\left(L_{o p t} s^{-1}\right)$ & 11.9 & 11.8 & 11.9 & 11.9 & 11.3 \\
\hline & $\mathrm{F}_{\mathrm{ecc}} / \mathrm{F}_{\mathrm{o}}(-)$ & 1.13 & 1.34 & 1.13 & 1.10 & 1.12 \\
\hline & $\mathrm{V}_{\mathrm{c}} / \mathrm{V}_{\max }(-)$ & 0.254 & 0.251 & 0.241 & 0.278 & 0.201 \\
\hline \multicolumn{2}{|c|}{$\begin{array}{l}\text { wRMSD score }(\mathrm{N} \cdot \mathrm{m}) \\
\text { (i.e., included } \theta_{\mathrm{K}} \text { only) }\end{array}$} & 16 & 20 & 13 & 17 & 17 \\
\hline \multirow{6}{*}{$\begin{array}{l}\text { wRMSD } \\
(\mathrm{N} \cdot \mathrm{m}) \\
\text { for the } \\
\text { individual } \\
\theta_{\mathrm{K}}\end{array}$} & $168^{\circ}$ & 17 & 19 & 13 & 16 & 17 \\
\hline & $155^{\circ}$ & 11 & 12 & 8 & 11 & 11 \\
\hline & $145^{\circ}$ & 13 & 14 & 10 & 13 & 13 \\
\hline & $135^{\circ}$ & 15 & 17 & 12 & 15 & 15 \\
\hline & $110^{\circ}$ & 11 & 16 & 9 & 11 & 12 \\
\hline & $45^{\circ}$ & 16 & 23 & 13 & 17 & 17 \\
\hline \multicolumn{2}{|c|}{$\begin{array}{l}\text { Overall wRMSD }(\mathrm{N} \cdot \mathrm{m}) \\
\text { (i.e., all } 6 \theta_{\mathrm{K}} \text { ) }\end{array}$} & 14 & 16 & 11 & 14 & 14 \\
\hline
\end{tabular}

Note. (1) Experimental: $2 \mathrm{a} \times \theta_{\mathrm{K}}=168^{\circ}$ and $45^{\circ}$. (2) In the third block of numbers, the gray boxes contain wRMSD values for knee angles that were not included in the optimization, and the white boxes contain values for knee angles that were included.

and $168^{\circ}$ ). This increase is similar in magnitude to previous studies that have measured plantar flexion torques at different knee angles; Cresswell et al. (1995) reported a $68 \%$ increase in plantar flexion torque over a knee angle range of $60^{\circ}$ to $180^{\circ}$ and Shinohara et al. (2006) reported a $43 \%$ increase between knee angles of $90^{\circ}$ and $180^{\circ}$. It is perhaps unsurprising that the optimization for the single (extended) knee angle, reflecting what is commonly used to obtain plantar flexion strength in torque-driven models, gave a reasonable fit to the experimental data for the four most extended knee positions but a much poorer fit for the two most flexed knee positions $\left(110^{\circ}\right.$ and $\left.45^{\circ}\right)$ where the gastrocnemius contribution becomes negligible (Table 2).
The muscle parameter values fell within the range reported in the literature (Cresswell et al., 1995; Muraoka et al., 2005). Maximum shortening velocities were similar to those currently used in simulation modeling (10-14 optimal fiber lengths per second) but higher than those obtained from in vitro measurements (Cook $\&$ McDonagh, 1996). The ratio of maximum isometric forces, $\left(\mathrm{F}_{\mathrm{o}} \mathrm{SOL} / \mathrm{F}_{\mathrm{o}} \mathrm{GAS}\right.$ ) was between 1.7 and 2.2 (Tables $2-3$ ), which is similar or slightly higher compared with typical PCSA ratios reported in literature based on in vivo measurements; for example, Albracht et al (2008) measured the ratio to be $1.6 \pm 0.4$ and Oliveira \& Menegaldo (2010), $1.7 \pm 0.5$. The ratio of maximum eccentric force 
a

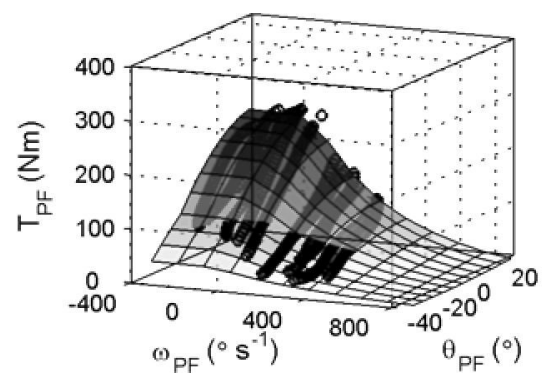

b

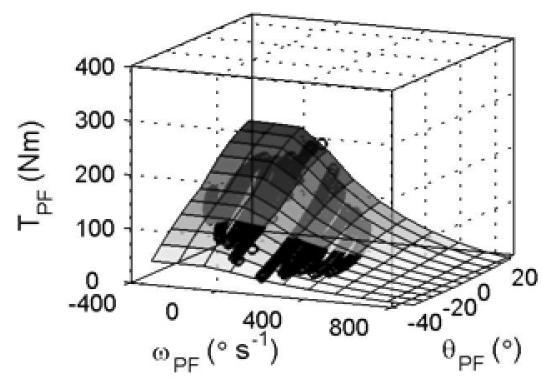

c

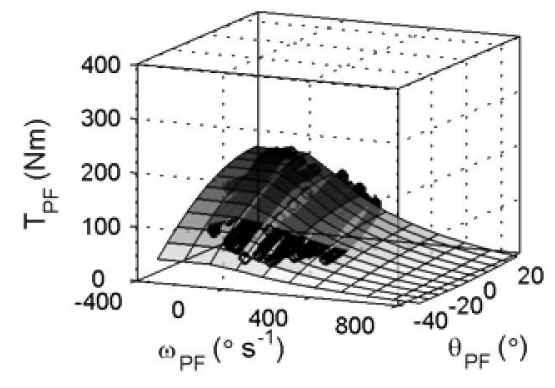

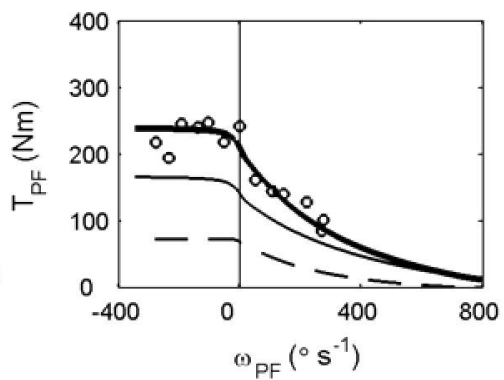
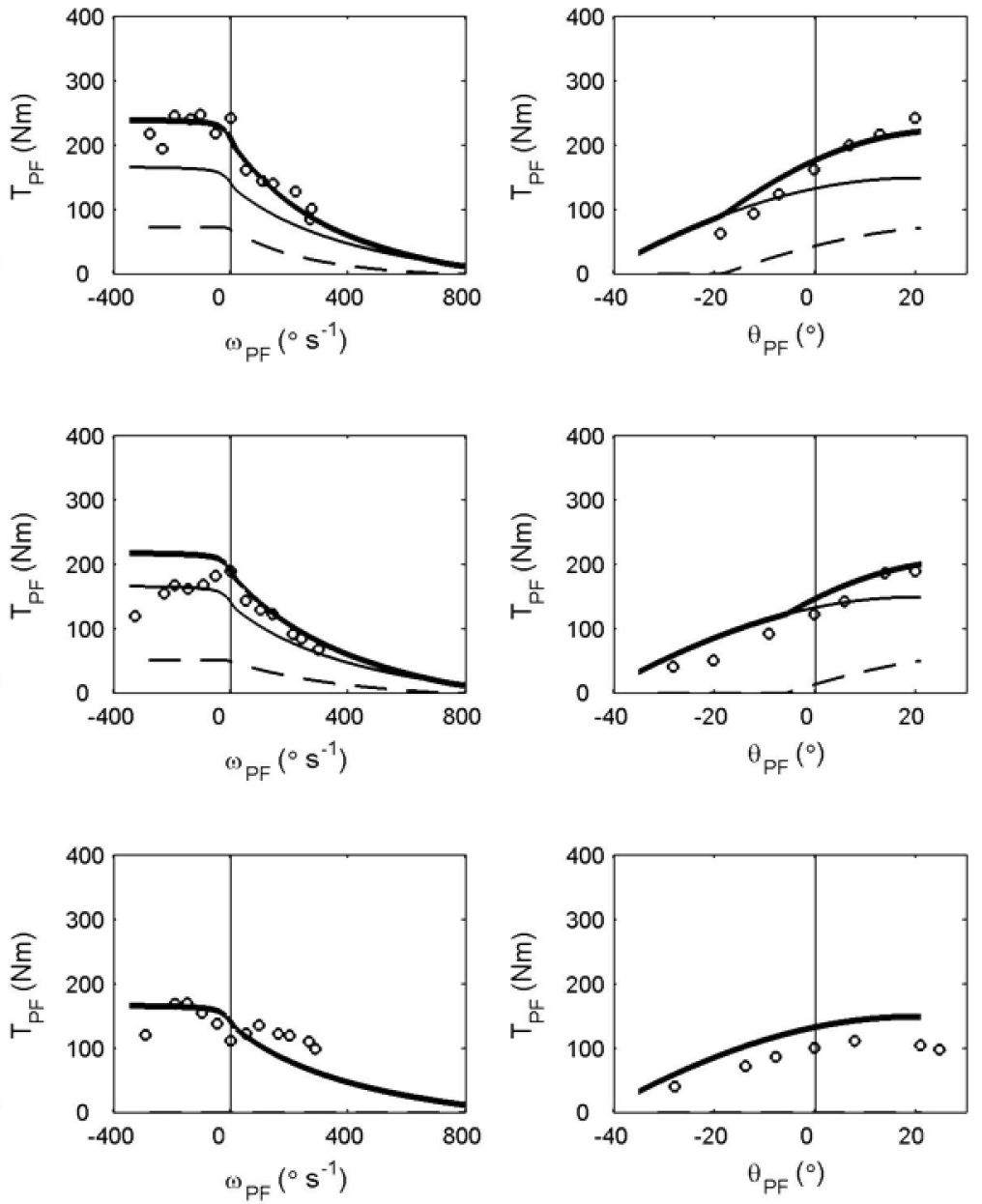

Figure 2 - Results from the optimizations using the data from all six knee angles. Maximum torque-angle-angular velocity and cross-sections through maximum torque-velocity and isometric torque-angle for knee angles of (a) $168^{\circ}$, (b) $135^{\circ}$, (c) $45^{\circ}$. The graphs illustrate the model predictions of total plantar flexion torque (thick solid line) and individual contributions of the soleus (thin solid line) and gastrocnemius (thin dashed line), and the corresponding experimental data (open circles).

to maximum isometric force $(1.1-1.4)$ was lower than that reported in the literature from in vitro measurements (1.5-1.8), which is unsurprising since in vivo measurements include neural inhibition (Westing et al., 1991). Soleus fiber length was greater than that of the gastrocnemius, in contrast to in vivo measurements reported in the literature (e.g., Maganaris et al., 1998; Chow et al., 2000); however, the paucity of in vivo measurement data on athletic subjects suggests that these deviations are not sufficient to indicate major concern. Furthermore, these comparisons should recognize the errors associated with both cadaver and in vivo direct measurements of muscle parameters (Cutts, 1988; Redl et al., 2007). Notably, although this study included validation of the individual muscle models obtained, there was no direct validation of the parameter values. Hence, the muscle parameters reported are not necessarily subject specific, only their combination in the form of the torque-angle-velocity muscle models. One option would be to use MRI to determine and/or validate some parameter values, as has been done in previous studies (Hasson et al., 2008).

A number of the individual muscle model assumptions require discussion. Firstly, it was assumed that the triceps surae generated the entire plantar flexion moment; that is, contributions from the other plantar flexors and antagonist muscle activity were neglected. The triceps surae accounts for approximately $90 \%$ of the total positive plantar flexion torque capacity (Spoor et al., 1990; Ward et al., 2009), while previous EMG measurements during maximal voluntary dynamometer strength testing have reported antagonist muscle activity to be negligible provided that the subject is accustomed to maximal dynamometer testing (Winter \& Challis, 2008; Forrester and Pain, 2010). 
a

b
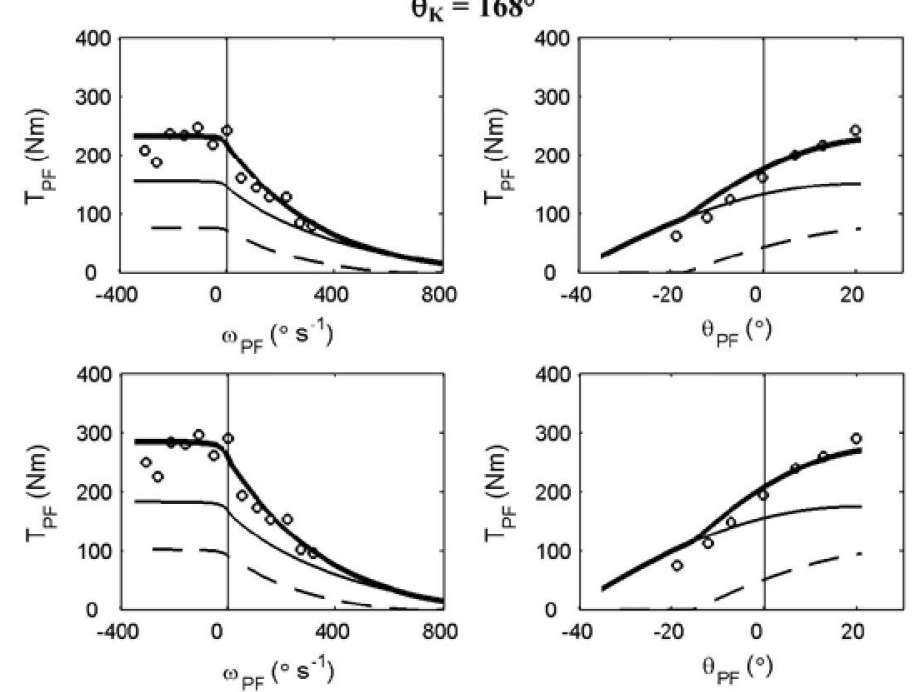

c

d
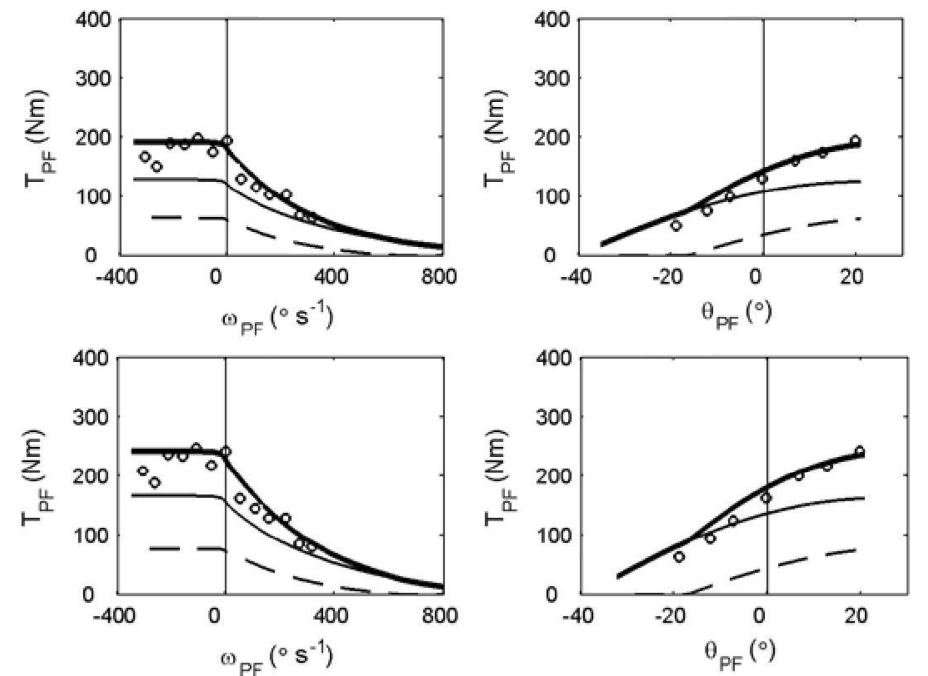

e
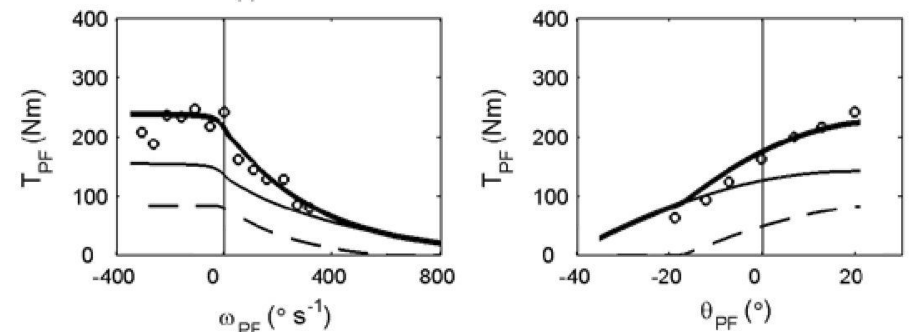

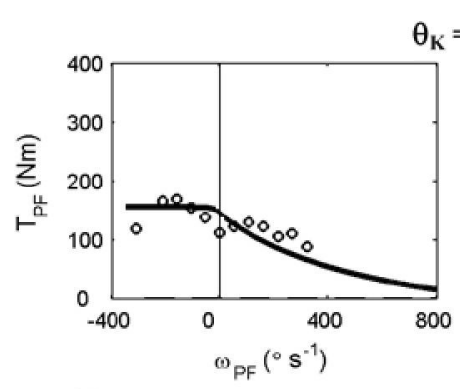

$\theta_{K}=45^{\circ}$
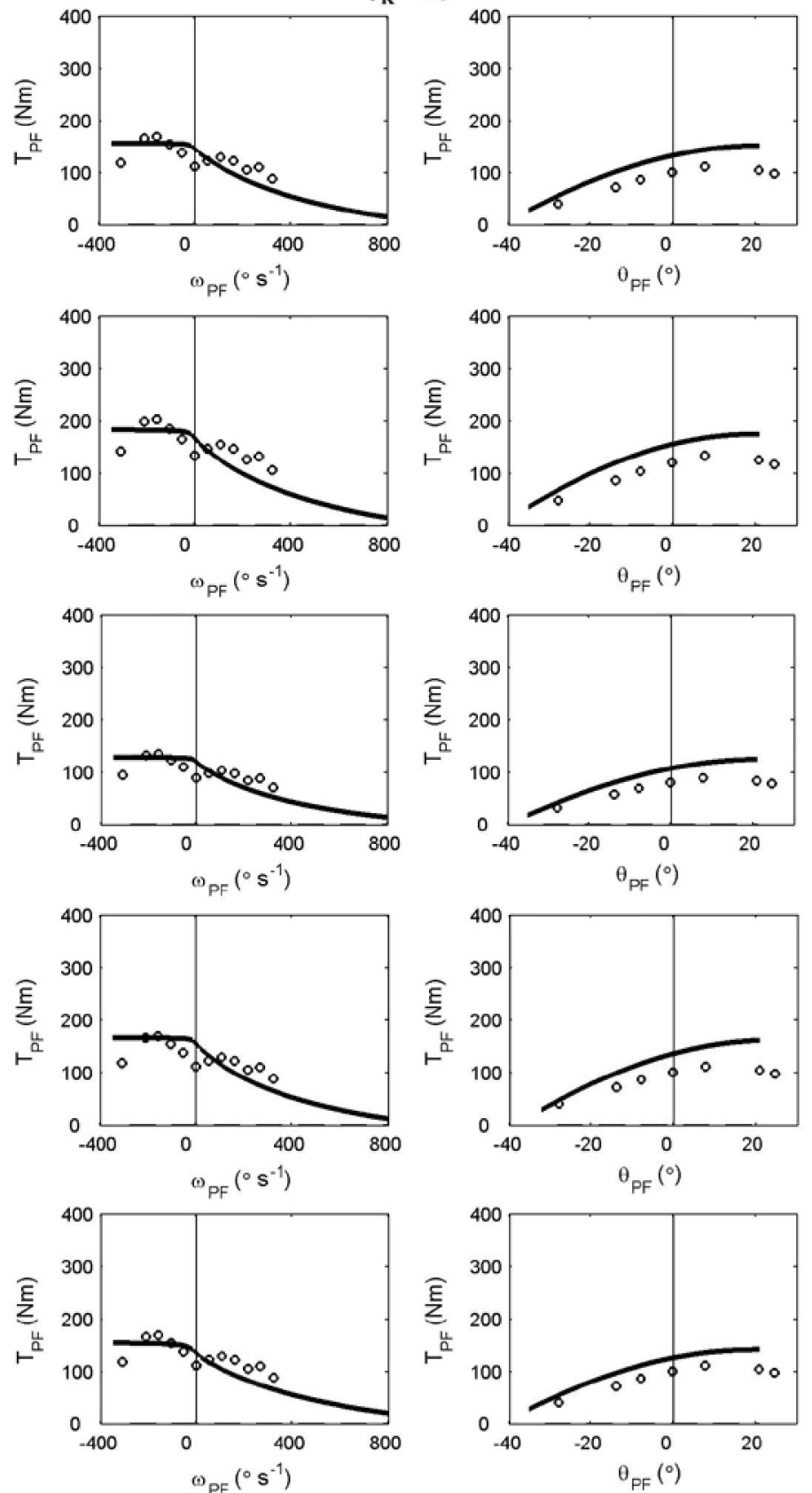

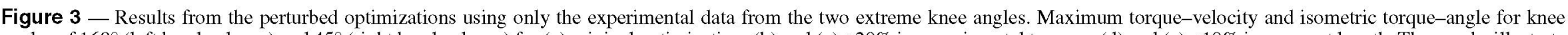

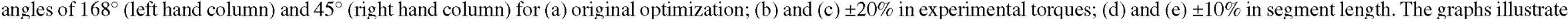

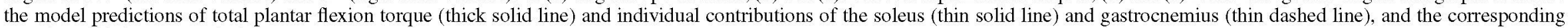
experimental data (open circles). 
Secondly, the medial and lateral heads of the gastrocnemius were combined. Both heads have very similar flexion-extension plane moment arms over the working knee angle range $\left(\sim 175^{\circ}\right.$ to $55^{\circ}$; Buford et al., 1997) and to separate the heads would have required the use of literature data for their relative contributions, compromising the subject-specific nature of the resulting muscle models. Thirdly, scaling moment arms and muscle-tendon unit lengths based on subject segment lengths is reported to work well for some joints (elbow: Murray et al., 2002) but not others (knee extensors: O'Brien et al., 2009) with the situation for the plantar flexors unclear. In this study, the subject had similar anthropometrics to the data from which the values were scaled, suggesting that any errors associated with the scaling method are likely to have been small. However, when this is not the case, then alternative means for estimating moment arms and muscle-tendon unit lengths may need to be investigated, such as by using MRI (Sheehan, 2007).

The methodology was developed from measurements on a single subject. From previous work it is expected that very similar experimental maximum torque-velocity-angle relations would be obtained from other subjects (Anderson et al., 2007). Hence the results from the range of optimizations in this study support the robustness of the proposed methodology and applicability to a wider population. Additional subjects would add little to the current study, but in future work it may be of interest to compare intersubject variability in individual muscle models.

The results presented herein support the robustness of the proposed methodology for determining subjectspecific individual muscle models for the ankle plantar flexors. Furthermore, this methodology can realistically be applied in muscle-driven computer simulation models of human movement and has the potential to improve their validity. The proposed approach generates individual muscle models that provide maximum strength (at the joint and muscle level) that is specific to that subject, in contrast to literature-based muscle models, which may not provide accurate maximum strength representation for the subject. This is particularly relevant when applying computer simulation modeling to maximal movements where strength and power limitations are likely to affect the outcome of a simulation and optimization.

\section{Acknowledgments}

The authors would like to acknowledge the financial support provided by the Foundation of Science and Technology of Portugal and the advice given by João Carvalho from the Department of Physics, University of Porto, during discussions on the model and genetic optimization.

\section{References}

Albracht, K., Arampatzis, A., \& Baltzopoulos, V. (2008). Assessment of muscle volume and physiological crosssectional area of the human triceps surae muscle in vivo. Journal of Biomechanics, 41, 2211-2218. PubMed doi:10.1016/j.jbiomech.2008.04.020

Anderson, D.E., Madigan, M.L., \& Nussbaum, M.A. (2007). Maximum voluntary joint torque as a function of joint angle and angular velocity: Model development and application to the lower limb. Journal of Biomechanics, 40 , 3105-3113. PubMed doi:10.1016/j.jbiomech.2007.03.022

Böhm, H., Cole, G.K., Brüggemann, G.P., \& Ruder, H. (2006). Contribution of muscle series elasticity to maximum performance in drop jumping. Journal of Applied Biomechanics, 22, 3-13. PubMed

Buford, W.L., Ivey, F.M., Malone, J.D., Patterson, R.M., Pearce, G.L., Nguyen, D.K., \& Stewart, A.A. (1997). Muscle Balance at the knee-moment arms for the normal knee and the ACL-minus knee. IEEE Transactions on Rehabilitation Engineering, 5, 367-379. PubMed doi:10.1109/86.650292

Chipperfield, A., Fleming, P., Pohlheim, H., \& Fonseca, C. (1994). Genetic Algorithm Toolbox for use with Matlab. User's Guide. UK: University of Sheffield.

Chow, R.S., Medri, M.K., Martin, D.C., Leekam, R.N., Agur, A.M., \& McKee, N.H. (2000). Sonographic studies of human soleus and gastrocnemius muscle architecture: gender variability. European Journal of Applied Physiology, 82, 236-244. PubMed doi:10.1007/s004210050677

Cook, C.S., \& McDonagh, M.J. (1996). Force responses to constant-velocity shortening of electrically stimulated human muscle-tendon complex. Journal of Applied Physiology, 81, 384-392. PubMed

Cresswell, A.G., Löscher, W.N., \& Thorstensson, A. (1995). Influence of gastrocnemius muscle length on triceps surae development and electromyographic activity in man. Experimental Brain Research, 105, 283-290. PubMed doi:10.1007/BF00240964

Cutts, A. (1988). Shrinkage of muscles fibres during the fixation of cadaveric tissue. Journal of Anatomy, 160 , 75-78. PubMed

Finni, T., \& Komi, P.V. (2002). Two methods for estimating tendinous tissue elongation during human movement. Journal of Applied Biomechanics, 18, 180-188.

Forrester, S.E., \& Pain, M.T.G. (2010). A combined muscle model and wavelet approach to interpreting the surface EMG signals from maximal dynamic knee extensions. Journal of Applied Biomechanics, 26, 62-72. PubMed

Forrester, S.E., Yeadon, M.R., King, M.A., \& Pain, M.T.G. (2011). Comparing different approaches for determining joint torque parameters from isovelocity dynamometer measurements. Journal of Biomechanics, 44, 955-961. PubMed doi:10.1016/j.jbiomech.2010.11.024

Friederich, J.A., \& Brand, R.A. (1990). Muscle fiber architecture in the human lower limb. Journal of Biomechanics, 23, 91-95. PubMed doi:10.1016/0021-9290(90)90373-B

Hasson, C.J., Miller, R.H., \& Caldwell, G.E. (2008). Determination of subject-specific mechanical properties of individual ankle joint muscles. In Proceedings of the North American Congress on Biomechanics. University of Michigan, Michigan.

Haupt, R.L., \& Haupt, S.E. (2004). Practical Genetic Algorithms (2nd ed.). New Jersey: John Wiley \& Sons, Inc.

Huxley, A.F. (1957). Muscle structure and theories of contraction. Progress in Biophysics and Biophysical Chemistry, 7, 225-318.

Jacobs, R., Bobbert, M.F., \& van Ingen Schenau, G.J. (1996). Mechanical output from individual muscles during explosive extensions: The role of biarticular muscles. Journal 
of Biomechanics, 29, 513-523. PubMed doi:10.1016/00219290(95)00067-4

King, M.A., Wilson, C., \& Yeadon, M.R. (2006). Evaluation of a torque-driven computer model of jumping for height. Journal of Applied Biomechanics, 22, 264-274. PubMed

Maganaris, C.N., Baltzopoulos, V., \& Sargeant, A.J. (1998). In vivo measurements of the triceps surae complex architecture in man: implications for muscle function. The Journal of Physiology, 512, 603-614. PubMed doi:10.1111/j.1469-7793.1998.603be.x

Muraoka, T., Chino, K., Muramatsu, T., Fukunaga, T., \& Kanehisa, H. (2005). In vivo passive mechanical properties of the human gastrocnemius muscle belly. Journal of Biomechanics, 38, 1213-1219. PubMed doi:10.1016/j. jbiomech.2004.06.012

Murray, W.M., Buchanan, T.S., \& Delp, S.L. (2002). Scaling of peak moment arms of elbow muscles with upper extremity bone dimensions. Journal of Biomechanics, 35, 19-26. PubMed doi:10.1016/S0021-9290(01)00173-7

O'Brien, T.D., Reeves, N.D., Baltzopoulos, V., Jones, D.A., \& Maganaris, C.N. (2009). Moment arms of the knee extensor mechanism in children and adults. Journal of Anatomy, 215, 198-205. PubMed doi:10.1111/j.14697580.2009.01088.x

Oliveira, L.F., \& Menegaldo, L.L. (2010). Individual-specific muscle maximum force estimation using ultrasound for ankle joint torque prediction using an EMG-driven Hilltype model. Journal of Biomechanics, 43, 2816-2821. PubMed doi:10.1016/j.jbiomech.2010.05.035

Red1, C., Gfoehler, M., \& Pandy, M.G. (2007). Sensitivity of muscle force estimates to variations in muscle-tendon properties. Human Movement Science, 26, 306-319. PubMed doi:10.1016/j.humov.2007.01.008

Rugg, S.G., Gregor, R.J., Mandelbaum, B.R., \& Chius, L. (1990). In vivo moment arm calculations at the ankle using magnetic resonance imaging (MRI). Journal of Biomechanics, 23, 495-501. PubMed doi:10.1016/0021-9290(90)90305-M

Scovil, C.Y., \& Ronsky, J.L. (2006). Sensitivity of a Hill-based muscle model to perturbations in model parameters. Journal of Biomechanics, 39, 2055-2063. PubMed doi:10.1016/j.jbiomech.2005.06.005

Sheehan, F.T. (2007). The 3D patellar tendon moment arm: quantified in vivo during volitional activity. Journal of Biomechanics, 40, 1968-1974. PubMed doi:10.1016/j. jbiomech.2006.09.029
Shinohara, M., Yoshitake, Y., Kouzaki, M., \& Fukunaga, T. (2006). The medial gastrocnemius muscle attenuates force fluctuations during plantar flexion. Experimental Brain Research, 169, 15-23. PubMed doi:10.1007/ s00221-005-0119-6

Spoor, C.W., van Leeuwen, J.L., Meskers, C.G.M., Titulaer, A.F., \& Huson, A. (1990). Estimation of instantaneous moment arms of lower leg muscles. Journal of Biomechanics, 23, 1247-1259. PubMed doi:10.1016/0021-9290(90)90382-D

Visser, J.J., Hoogkamer, J.E., Bobbert, M.F., \& Huijing, P.A. (1990). Length and moment arm of human leg muscles as a function of knee and hip-joint angles. European Journal of Applied Physiology, 61, 453-460. PubMed doi:10.1007/BF00236067

Ward, S.R., Eng, C.M., Smallwood, L.H., \& Lieber, R.L. (2009). Are current measurements of lower extremity muscle architecture accurate? Clinical Orthopaedics and Related Research, 467, 1074-1082. PubMed doi:10.1007/ s11999-008-0594-8

Westing, S.H., Cresswell, A.G., \& Thorstensson, A. (1991). Muscle activation during maximal voluntary eccentric and concentric knee extension. European Journal of Applied Physiology, 62, 104-108. PubMed doi:10.1007/ BF00626764

Winters, J.M., \& Woo, S.L. (1990). Multiple Muscle Systems. Biomechanics and Movement Organization. New York: Springer-Verlag.

Winter, S.L., \& Challis, J.H. (2008). Reconstruction of the human gastrocnemius force-length curve in vivo: Part 2 - experimental results. Journal of Applied Biomechanics, 24, 207-214. PubMed

Wood, G.A., \& Jennings, L.S. (1979). On the use of spline functions for data smoothing. Journal of Biomechanics, 12, 477-479. PubMed doi:10.1016/0021-9290(79)90033-2

Yeadon, M.R., \& Challis, J.H. (1994). The future of performance-related sports biomechanics research. Journal of Sports Sciences, 12, 3-32. PubMed doi:10.1080/02640419408732156

Yeadon, M.R., King, M.A., \& Wilson, C. (2006). Modelling the maximum voluntary joint torque/angular velocity relationship in human movement. Journal of Biomechanics, 39, 476-482. PubMed doi:10.1016/j. jbiomech.2004.12.012 